5. Kasite. I, Bejan-Angoulvant.T, Lardy.H et al (2018), A systematic review of the learning curve in robotic surgery: range and herterogeneity, Surgical Endoscopy, 33:353-365.

6. Raimondi.P, Marchegiani.F, Cieri.M et al (2017), Is right colectomy a complete learning procedure for a robotic surgical program? , J Robotic Surg, Doi 10.1007/s117017-017-0711-3.

7. Soomro.N.A, Hashimoto.A.D, Porteous.A.J et al (2020), Systematic review of learning curves in robot - assisted surgery, BJS Open 4:27-44.

\title{
MộT SỐ YẾU TỐ LIÊN QUAN ĐẾN CĂNG THẲNG NGHỀ NGHIỆP CỦA NGƯỜI LAO ĐỘNG TỈNH ĐỒNG NAI NĂM 2020
}

\section{TÓM TẮT}

Mục tiêu: Mô tả một số yếu tố liên quan đến tình trang căng thẳng nghề nghiêpp của người lao động tại Cổng ty cổ phân gạch men Y Mỹ, tỉnh Đồng Nai năm 2020. Phương pháp: nghiên cứu cắt ngang. Kết quả: Tỷ lệ căng thẳng nghề nghiêp ở người lao đông là $13,5 \%$. Tỷ lệ này cao hơn ớ nhóm người lao động làm viêc trên 5 ngày/tuần $(18,2 \%)$, thường xuyên phải làm việc với khối lượng công việc vượt quá khả năng của bản thân $(50 \%)$, thường xuyên làm việc với cường độ cao (33,3\%), không được tạo điều kiện học tập $(17 \%)$ so với những người người lao động trong nhóm so sánh với giá trị $\mathrm{p}<0,05$. Nghiên cứu không tìm thấy mối liên quan giữa tình tranng căng thẳng nghề nghiệp với đặc điểm cá nhân của người lao đông. Kết luận: Có mối liên quan có ý nghĩa thống kê giữa tình trạng căng thẳng của người lao động với một số yếu tố như số ngày làm việc/tuân, khổi lượng công việc, cường độ làm việc, cơ hội được học tập.

Từ khóa: Căng thẳng nghề nghiệp, JCQ-V

\section{SUMMARY}

SEVERAL FACTORS RELATED TO

\section{OCCUPATIONAL STRESS OF DONG NAI} PROVINCE'S EMPLOYEES IN 2020

Objective: Describe some factors related to occupational stress of employees at $Y$ My Ceramic Joint-stock company, Dong Nai province in 2020. Method: Cross-sectional studies. Result: The proportion of workers got occupational stress is $13,5 \%$. This proportion is higher in subgroup of workers working for more than 5 days per week $(18,2 \%)$, subgroup of workers usually work under requirements higher than their capability $(50 \%)$, subgroup of workers usually work with high intensity $(33,3 \%)$, subgroup of workers not being given opportunity for higher learning $(17 \%)$, in comparison to workers in control group $(p<0,05)$. The study has not found the significant association between the prevalence of occupational stress and individual characteristics of employees. Conclusion: There was

*Viện Đào tạo YHDP \& YTCC, Đại học Y Hà Nội Chịu trách nhiệm chính: Dương Văn Quân Email: duongquanhmu@gmail.com Ngày nhận bài: 16.12 .2020

Ngày phản biện khoa họ: 26.01.2021

Ngày duyệt bài: 5.2.2021

\section{Dương Văn Quân*, Lê Thị Thanh Xuân*}

a statistically significant relationship between an employee's stress status and several factors such as number of working days / week, workload, intensity of work, opportunity to study.

Keywords: Occupational stress, JCQ-V

\section{I. ĐĂT VẤN ĐỀ}

Căng thẳng nghề nghiệp (hay stress nghề nghiệp) được định nghĩa là sự mất cân bằng giữa yêu câu lao động và khả nẳng lao động [1]. Ở Việt Nam, ngành gạch men đem lại nhiều giá trị về kinh tế - xã hội. Tuy đã có nhiều cải tiến trong guy trình sản xuất, nhưng ngành gạch men vân được coi là một ngành công nghiệp nặng với nhiều khâu sản xuất nguy hiểm, nặng nhọc. Chế độ làm việc ca kíp, cường độ lao động liên tuc và làm viêc trong thời gian dài nhất. Các yếu tố này có thể ảnh hưởng tiêu cực tới NLĐ gây ra căng thẳng nghề nghiệp, làm giảm năng suất lao động. Nhiêu nghiên cứu đã chỉ ra các yếu tố liên quan tới tình trạng căng thẳng nghề nghiệp là rất đa dạng, liên quan chủ yếu tới đăc điểm công việc, quan hệ với đồng nghiệp, các yếu tố gia đình và đời sống xã hội [2]. Tuy nhiên, thực tế lại chưa có nhiều nghiên cứu về mối liên quan này trên đối tượng NLĐ ngành công nghiệp nặng. Do đó, chúng tôi thực hiện nghiên cứu này với mục tiêu: "Mô tả một số yếu tố liên quan đến tình trạng căng thẳng nghề nghiệp của người lao động tại Công ty cổ phần gạch men Ý Mỹ, tỉnh Đồng Nai năm 2020".

\section{II. ĐỐI TƯƠNG VÀ PHƯƠNG PHÁP NGHIÊN CỨU \\ 2.1. Đối tượng nghiên cứu}

- Tiêu chuẩn lựa chọn: Người lao động trực tiếp tham gia vào dây chuyên sản xuất gạch men (bộ phận làm việc trực tiếp).

- Tiêu chuẩn loại trừ: NLĐ làm việc ở các bộ phận gián tiếp như phòng hành chính, nhân sự, quản lý...., vắng mặt tại thời điểm điêu tra.

\subsection{Phương pháp nghiên cứu}

2.2.1. Thiết kế nghiên cứu: Nghiên cứu mô tả cắt ngang

2.2.2. Cỡ mẫu: Toàn bộ NLĐ trực tiếp tham 
gia vào dây chuyền sản xuất gạch men (bộ phận làm việc trực tiếp).

2.2.3. Chọn mẫu: Lập danh sách toàn bộ NLĐ trực tiếp tham gia vào dây chuyền sản xuất, theo từng đơn vị. Chọn mẫu toàn bộ NLĐ đủ tiêu chuẩn tham gia nghiên cứu và đồng ý tham gia nghiên cứu, quá trình chọn mẫu đã chọn được 311 NLĐ.

\subsubsection{Thời gian và địa điểm nghiên cứu}

- Thời gian nghiên cứu: Từ tháng 3/2020 đến $5 / 2021$

- Địa điểm nghiên cứu: Công ty cổ phần gạch men Ý Mỹ, tỉnh Đồng Nai

2.2.5. Công cụ và phương pháp thu thập số liệu

Công cụ thu thập số liệu: sử dụng bộ câu hỏi JCQ-V để đánh giá tình trạng căng thẳng nghề nghiệp của NLĐ theo mô hình Karasek. Gồm 22 câu hỏi và đánh giá trên 3 khía cạnh: áp lực tâm lý, quyền quyết định và sự ủng hộ trong công việc.

- Phương pháp thu thập số liệu: số liệu được thu thập theo phương pháp tự điền vào phiếu câu hỏi dưới sự hướng dẫn và giám sát của điều tra viên.

2.3. Xử lý số liệu: Số liệu được nhập, làm sạch bằng phần mềm Epidata 3.1 và xử lý số liệu bằng phần mềm SPSS 20 để xác định tỷ lệ căng thẳng nghề nghiệp và một số yếu tố liên quan đến tình trạng căng thẳng.

2.4. Đạo đức nghiên cứu. Nghiên cứu hoàn toàn được sự đồng ý của lãnh đạo Công ty cổ phần gạch men Ý Mỹ, tỉnh Đồng Nai. Toàn bộ thông tin mà đối tượng cung cấp chỉ sử dụng cho mục đích nghiên cứu và được bảo mật tuyệt đối. Kết quả của nghiên cứu góp phần cải thiện sức khỏe của NLĐ tại công ty cổ phần gạch men Ý Mỹ, tỉnh Đồng Nai.

\section{KẾT QUẢ NGHIÊN CỨU}

Bảng 1: Đặc điểm chung của đôî tượng nghiên cứu

\begin{tabular}{|c|c|c|c|}
\hline Biến số & Đặc điểm & $\begin{array}{c}\text { Tân số } \\
\text { (n) }\end{array}$ & $\begin{array}{c}\text { Tỷ leế } \\
(\%)\end{array}$ \\
\hline \multirow{3}{*}{ Nhóm tuổi i } & $20-29$ tuối & 51 & 16,4 \\
\cline { 2 - 4 } & $30-39$ tuối & 120 & 38,6 \\
\cline { 2 - 4 } & $40-49$ tuối & 114 & 36,7 \\
\cline { 2 - 4 } & $\geq 50$ tuối & 26 & 8,4 \\
\hline
\end{tabular}

\begin{tabular}{|c|c|c|c|}
\hline & \multicolumn{3}{|c|}{$\begin{array}{c}\text { Tuối trung bình } \bar{X} \pm \text { SD (min-max): } \\
37,92 \pm 8,28(20-61)\end{array}$} \\
\hline \multirow{2}{*}{ Giới } & Nam & 273 & 87,8 \\
\hline & Nữ & 38 & 12,2 \\
\hline \multirow{3}{*}{$\begin{array}{l}\text { Tình trang } \\
\text { hôn nhân }\end{array}$} & Chưa kết hôn & 41 & 13,2 \\
\hline & Đã kết hôn & 261 & 83,9 \\
\hline & Góa, ly hôn, ly dị & 9 & 2,9 \\
\hline \multirow{4}{*}{$\begin{array}{l}\text { Trình độ } \\
\text { học vấn }\end{array}$} & TH/THCS & 131 & 42,1 \\
\hline & THPT & 111 & 35,7 \\
\hline & Sơ/trung cấp & 51 & 16,4 \\
\hline & $\mathrm{CÐ} / \mathrm{DH} / \mathrm{SÐH}$ & 18 & 5,8 \\
\hline \multirow{5}{*}{$\begin{array}{c}\text { Nhóm tuổi } \\
\text { nghề }\end{array}$} & $<1$ năm & 3 & 1,0 \\
\hline & $1-9$ năm & 177 & 56,9 \\
\hline & 10 - 19 năm & 107 & 34,4 \\
\hline & $\geq 20$ năm & 24 & 7,7 \\
\hline & \multicolumn{3}{|c|}{$\begin{array}{c}\text { Tuối nghề trung bình } \bar{X} \pm \text { SD } \\
\text { (min-max): } 9,13 \pm 6,20{ }_{(0,2-35)}\end{array}$} \\
\hline & Tống & 311 & 100,0 \\
\hline
\end{tabular}

Phần lớn NLĐ nằm trong nhóm tuối từ 30-39 tuổi $(38,6 \%)$ và 40-49 tuổi $(36,7 \%)$, tuổi trung bình là 37,92 tuổi, thấp nhất là 20, lớn nhất là 61. Nam giới chiếm tỷ lệ cao hơn so với nữ giới $(87,8 \%$ và $12,2 \%)$. Trình độ học vấn của NLĐ là tiểu học/THCS chiếm tỷ lệ cao nhất $(42,1 \%)$, THPT $(35,7 \%)$, sơ/trung cấp $(16,4 \%)$, thấp nhất là cao đẳng/đại học $(5,8 \%)$. Nhóm NLĐ làm việc từ 1-9 năm chiếm tỳ lệ cao nhất với $56,9 \%$ và thấp nhất là nhóm có tuổi nghề < 1 năm chiếm $1,0 \%$. Số năm làm việc trung bình của NLĐ là 9,13 năm, cao nhất là 35 năm và thấp nhất là 0,2 năm.

Bảng 2: Mức độ căng thẳng nghề nghiệp của NLĐ theo mô hình Karasek

\begin{tabular}{|c|c|c|c|c|}
\hline \multirow{2}{*}{$\begin{array}{l}\text { Áp lực } \\
\text { tâm lý }\end{array}$} & \multicolumn{4}{|c|}{ Quyên quyết định } \\
\hline & \multicolumn{2}{|c|}{ Thấp } & \multicolumn{2}{|c|}{ Cao } \\
\hline \multirow{3}{*}{ Thấp } & Công $v$ & hụ động & Công vi & hoải mái \\
\hline & $\mathbf{n}$ & $\%$ & n & $\%$ \\
\hline & 4 & 1,3 & 8 & 2,6 \\
\hline \multirow{3}{*}{ Cao } & \multicolumn{2}{|c|}{ Công việc căng thắn } & \multicolumn{2}{|c|}{ Công việc chủ động } \\
\hline & $\mathbf{n}$ & $\%$ & $n$ & $\%$ \\
\hline & 42 & 13,5 & 257 & 82,6 \\
\hline
\end{tabular}

Theo mô hình Karasek, nhóm NLĐ làm công việc chủ động chiếm tỷ lệ cao nhất với $82,6 \%$, tiểp đến là nhóm cảm nhận công việc của họ căng thẳng (áp lực tâm lý cao và quyền quyết định thấp) chiếm $13,5 \%$, nhóm làm công việc thoải mái với $2,6 \%$ và nhóm NLĐ làm công việc thụ động chiếm tỷ lệ thấp nhất với 1,3\%.

Bảng 3: Môi liên quan giữa tình trạng căng thẳng với đặc điểm cá nhân

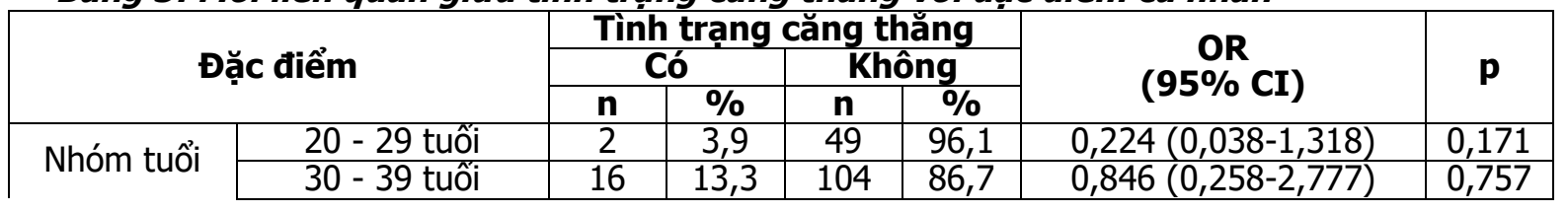




\begin{tabular}{|c|c|c|c|c|c|c|c|}
\hline & $40-49$ tuối & 20 & 17,5 & 94 & 82,5 & $1,170(0,363-3,769)$ & 1,000 \\
\hline & $\geq 50$ tuối & 4 & 15,4 & 22 & 84,6 & 1 & \\
\hline \multirow{2}{*}{ Giới } & Nam & 36 & 13,2 & 237 & 86,8 & $0,810(0,317-2.073)$ & \multirow{2}{*}{0,660} \\
\hline & Nũ̃ & 6 & 15,8 & 32 & 84,2 & 1 & \\
\hline \multirow{4}{*}{$\begin{array}{l}\text { Trình độ } \\
\text { học vấn }\end{array}$} & TH/THCS & 21 & 16,0 & 110 & 84,0 & $3,245(0,409-25,722)$ & 0,475 \\
\hline & THPT & 14 & 12,6 & 97 & 87,4 & $2,454(0,303-19,900)$ & 0,693 \\
\hline & Sơ/trung cấp & 6 & 11,8 & 45 & 88,2 & $2,267(0,254-20,239$ & 0,667 \\
\hline & $\mathrm{CÐ} / \mathrm{DH} / \mathrm{S} \oplus \mathrm{H}$ & 1 & 5,6 & 17 & 94,4 & 1 & \\
\hline \multirow{2}{*}{$\begin{array}{l}\text { Tình trang } \\
\text { hôn nhân }\end{array}$} & Đã kết hôn & 36 & 13,8 & 225 & 86,2 & $0,852(0,339-2,144)$ & \multirow[b]{2}{*}{0,734} \\
\hline & $\begin{array}{l}\text { Chưa kết hôn/ } \\
\text { Góa, ly hôn, ly di }\end{array}$ & 6 & 12,0 & 44 & 88,0 & 1 & \\
\hline \multirow{4}{*}{$\begin{array}{c}\text { Nhóm tuối } \\
\text { nghề }\end{array}$} & $<1$ năm & 0 & 0,0 & 3 & 100, & - & 1,000 \\
\hline & $1-9$ năm & 19 & 10,7 & 158 & 89,3 & $0,601(0,186-1,946)$ & 0,490 \\
\hline & $10-19$ năm & 19 & 17,8 & 88 & 82,2 & $1,080(0,331-3,522)$ & 1,000 \\
\hline & $\geq 20$ năm & 4 & 16,7 & 20 & 83,3 & 1 & \\
\hline
\end{tabular}

Kết quả cho thấy không có mối liên quan có ý nghĩa thống kê giữa tình trạng căng thằng trong công việc với các yếu tố: tuổi, giới, tuổi nghề, tình trạng hôn nhân, trình độ học vấn với $p>0,05$.

Bảng 4: Mối liên quan giữa tình trạng căng thẳng với đặc điểm công việc

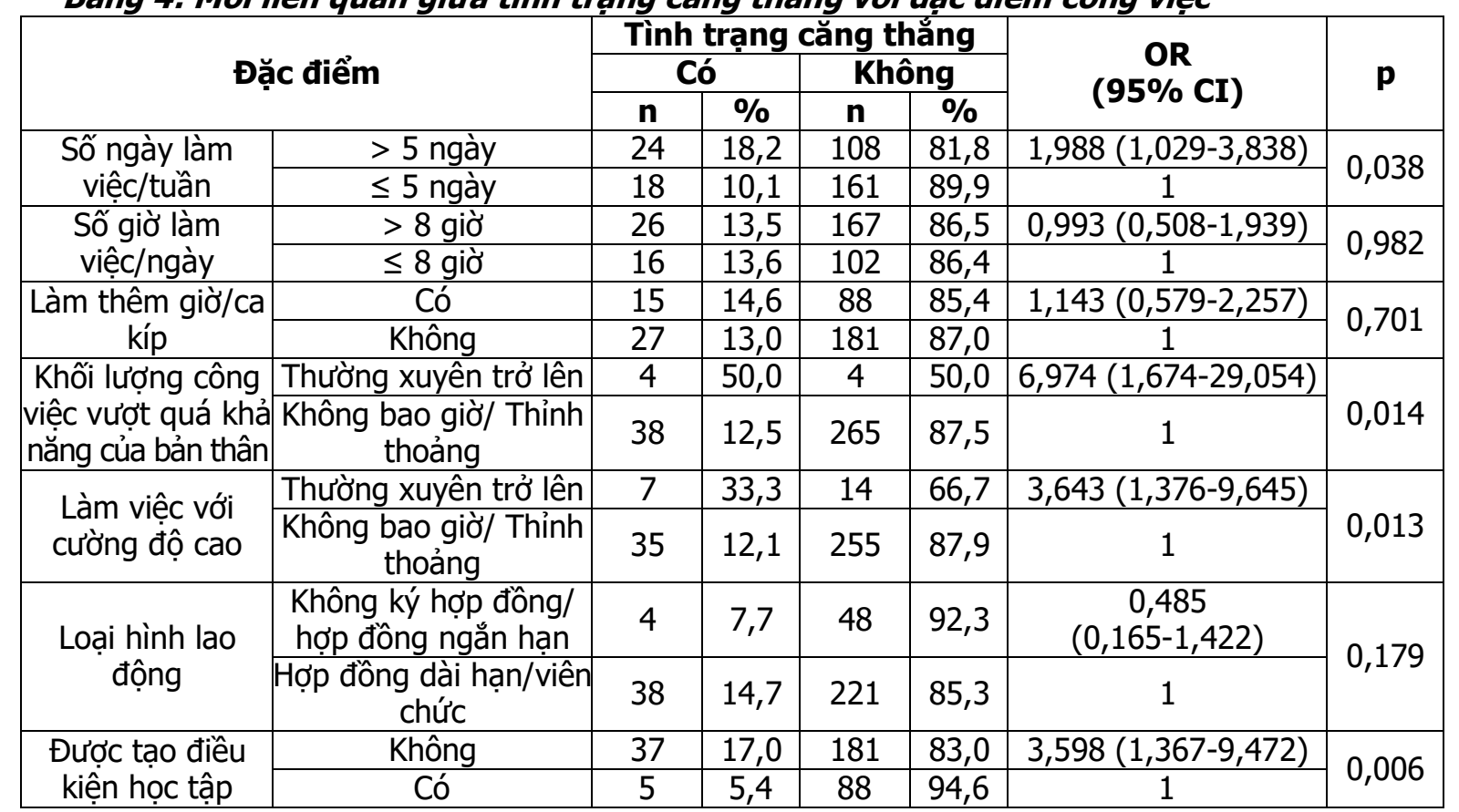

Nhóm NLĐ làm việc $>5$ ngày/tuần có nguy cơ căng thẳng gấp 1,988 lần so với nhóm làm việc $\leq 5$ ngày/tuần $(95 \%$ CI: $1,029-3,838 ; p=$ $0,038<0,05)$. NLĐ thường xuyên phải làm việc với một khối lượng công việc vượt quá khả năng của bản thân có nguy cơ căng thẳng cao gấp 6,974 lần so với nhóm NLĐ cho rằng họ không hoặc thỉnh thoảng phải làm công việc vượt quá khả năng bản thân $(95 \% \mathrm{CI}: 1,674-29,054, \mathrm{p}=$ $0,014<0,05)$. Nguy cơ căng thẳng trong công việc ở nhóm NLĐ thường xuyên phải làm việc với cường độ cao gấp 3,643 lần so với nhóm NLĐ cho rằng họ không hoặc thỉnh thoảng phải làm việc với cường độ cao (95\%CI: 1,376 - 9,645, p
$=0,013<0,05)$. Những NLĐ không được taoo điều kiện học tập có nguy cơ căng thẳng gấp 3,598 lần so với nhóm NLĐ được tạo điều kiện học tập (95\%CI: 1,367-9,472; $p=0,006<0,05)$.

\section{BÀN LUÂ̂N}

Tỷ lệ căng thẳng nghề nghiệp của NLĐ tại Công ty cổ phần gạch men Ý Mỹ là $13,5 \%$, tỷ lệ này thấp hơn so với nghiên cứu của Nguyến Thị Thuỳ Linh năm 2012 trên đối tượng NLĐ nhà máy da giầy tại Hải Phòng cũng sử dụng thang đo JCQ-V $(20,7 \%)$ [3]. Sự khác biệt này có thể là do đối tượng nghiên cứu khác nhau. Nghiên cứu của chúng tôi tiến hành trên NLĐ ngành sản 
xuất gạch men, đây là ngành công nghiệp chủ yếu sử dụng NLĐ là nam giới, trong khi đó nghiên cứu của Nguyễn Thị Thuỳ Linh chủ yếu NLĐ là nữ giới. Thực tế cho thấy nữ giới thường bị căng thẳng nhiều hơn so với nam giới. Bởi họ phải chịu nhiêu áp lực không chỉ trong công việc mà cả trong cuộc sống hàng ngày. Hơn nữa do tính chất công việc giữa các nghiên cứu có sự khác biệt.

Nghiên cứu của chúng tôi chưa tìm thãy mối liên quan có ý nghĩa thống kê giữa tình trạng căng thẳng trong công việc với các yếu tố về đặc điểm cá nhân của NLĐ $(p>0,05)$. Tuy chưa tìm thấy mối liên quan có ý nghĩa thống kê nhưng một số nghiên cứu trước đây đã chỉ ra rằng các yếu tố như tuổi, giới, tình trạng hôn nhân là những yếu tố nguy cơ của căng thẳng nghề nghiệp [4],[5].

So với nhóm NLĐ làm việc $\leq 5$ ngày/tuần thì nhóm NLĐ làm việc > 5 ngày/tuần có nguy cơ mắc căng thẳng nghề nghiệp cao gấp 1,988 lần ( $95 \% \mathrm{CI}: 1,029-3,838)$. Điều này là hoàn toàn phù hợp với thực tế, khi số ngày làm việc tăng sẽ làm tăng nguy cơ NLĐ phải đối diện với nhiều khó khăn trong công việc cộng thêm việc họ không được hố trợ đây đủ như chế độ bồi dưỡng, trợ cấp, nghỉ ngơi thì chắc chắn việc tăng số ngày lao động sẽ làm tăng nguy cơ căng thẳng.

Những NLĐ thường xuyên phải đối mặt với khối lượng công việc vượt quá khả năng bản thân có nguy cơ căng thẳng gấp 6,974 lần so với nhóm cảm nhận không bao giờ/thỉnh thoảng có khối lượng công việc vượt quá khả năng (95\%CI: 1,674 - 29,054). Nhiều nghiên cứu cũng tìm thấy mối liên quan giữa tình trang căng thẳng với khối lượng công việc. Cụ thể: nghiên cứu của $\mathrm{He} L$ và cộng sự năm 2016 tại Trung quốc, sử dụng bộ công cụ JCQ, nghiên cứu đã chỉ ra rằng khối lượng công việc có ảnh hưởng lớn đến sự căng thẳng nghề nghiệp của điều dưỡng, khối lượng công việc tăng lên có thể dẫn đến phản ứng căng thẳng mạnh hơn, giảm khả năng phục hồi cơ thể [6].

Nguy cơ mắc căng thẳng nghề nghiệp tăng lên ở nhóm NLĐ thường xuyên phải làm việc với cường độ cao ( $\mathrm{OR}=3,643 ; 95 \% \mathrm{CI}$ : 1,376 $9,645)$. Điều này có thể là do NLĐ ngành gạch men luôn phải đối mặt với một cường độ lao động cao không chỉ vể mặt thể chất mà còn cả về mặt tinh thần. Kết quả này cũng giống với nghiên do Nguyễn Thu Hà thực hiện năm 2017, nghiên cứu đã chỉ ra một sổ yếu tố liên quan đên tình trạng căng thẳng như các yếu tố không thuận lợi trong môi trường lao động, sự quá tải trong công việc (khối lượng công việc nhiều, cường độ làm việc lớn, thời gian làm việc kéo dài, trách nhiệm công việc cao) $(p<0,05)$ [2],[7].

Nghiên cứu đã phát hiện ra rằng những NLĐ không được tạo điều kiện học tập có nguy cơ căng thẳng gấp 3,598 lần so với nhóm được tạp điểu kiện học tập (95\%CI: 1,367 - 9,472). Khi NLĐ được tạo cơ hội học tập sẽ giúp họ nâng cao tay nghể và có thể tự tin vào khả năng làm việc của mình. Hơn nữa việc NLĐ được tạo điều kiện học tập chứng tỏ một điều là họ nhận được sự tín nhiệm của cấp trên nên họ sẽ nố lực, cống hiến cho tổ chức.

\section{KẾT LUÂN}

Tỷ lệ căng thẳng nghề nghiệp của NLĐ tại Công ty cổ phần gạch men Ý Mỹ, tỉnh Đồng Nai là $13,5 \%$. Các yếu tố gây căng thẳng trong công việc ảnh hưởng đến NLĐ bao gồm một số yếu tố như số ngày làm việc/tuần, khối lượng công việc, cường độ lao động và được tạo điều kiện học tập. Ban lãnh đạo cần tiến hành sàng lọc, phát hiện sớm những NLĐ có biểu hiện của cẳng thẳng để điều trị sớm và giảm gánh nặng cho gia đình và xã hội. Đối với NLĐ cần tăng cường trao đổi, chia sẻ kinh nghiệm cũng như hỗ trợ lẫn nhau trong quá trình làm việc. Các nghiên cứu tiếp theo cần thống nhất một bộ công cụ nhất quán cho việc nghiên cứu về cằng thẳng nghề nghiệp của NLĐ sau này.

\section{TÀl LIÊUU THAM KHẢO}

1. Bộ môn Sức khỏe nghề nghiệp. Sức khỏe nghề nghiệp, Nhà xuất bản Y học; 2018.

2. Nguyển Thu Hà. Điều tra stress nghề nghiệp ở nhân viên y tế. Tạp chí $Y$ học Việt Nam. 2017;454(1):231-234.

3. Phạm Văn Hán, Phạm Minh Khuê và Nguyễn Thị Thuỳ Linh. Căng thẳng nghề nghiệp trên NLĐ nhà máy da giầy Lể Lai 2 Hải Phòng năm 2012. Tạp chí Y học dự phòng. 2014; XXIV, 9(158):9.

4. Trinh Hông Lân. Stress nghề nghiệp ở công nhân ngành may công nghiệp. Tạp chí Y học TP Hồ Chí Minh. 2010;14 (1):217-221.

5. Nguyê̂n Thị Hường. Stress nghề nghiệp của người lao động trong các doanh nghiệp tư nhân trên địa bàn thành phố Hà Nội, Đại học Khoa học Xã hội và Nhân văn, Đại học Quốc gia Hà Nội; 2010.

6. CL. Żhang, L. He, T. Yang, YJ. Lan. Relationship between occupational stress, recovery experience, and physiological health of nurses in a municipal grade A tertiary hospital. Zhonghua Lao Dong Wei Sheng Zhi Ye Bing Za Zhi. 2017;35(6):425-428.

7. K. Seto, S. Ito, S. Fujita et al. Occupational stress among healthcare workers in Japan. Work. 2014;49(2):225-234. 